\title{
Características morfogênicas e estruturais de capim-massai submetido a adubação nitrogenada e desfolhação ${ }^{1}$
}

\author{
Janaina Azevedo Martuscello ${ }^{2}$, Dilermando Miranda da Fonseca ${ }^{3}$, Domicio do Nascimento \\ Júnior $^{3}$, Patrícia Menezes Santos ${ }^{4}$, Daniel de Noronha Figueiredo Vieira da Cunha ${ }^{2}$, \\ Luciano de Melo Moreira ${ }^{5}$
}

\author{
${ }^{1}$ Parte da dissertação do primeiro autor, apresentada ao Programa de Pós-graduação em Zootecnia da UFV. \\ 2 Programa de Pós-graduação em Zootecnia/UFV. \\ ${ }^{3}$ Departamento de Zootecnia/UFV. \\ 4 EMBRAPA Pecuária Sudeste. \\ ${ }^{5}$ FEAD - Minas. Av. Brasil, 1879 - Funcionários, Belo Horizonte - MG
}

RESUMO - O trabalho foi realizado com o objetivo de avaliar as características morfogênicas de Panicum maximum x Panicum infestum cv. Massai submetido a quatro doses de nitrogênio $\left(0,40,80\right.$ e $\left.120 \mathrm{mg} / \mathrm{dm}^{3}\right)$ e três regimes de desfolhação (três, quatro e cinco folhas completamente expandidas), em um esquema fatorial 4 x 3 , em um delineamento inteiramente casualizado, com quatro repetições. Após semeadura, transplantio e desbaste, três plantas permaneceram em vasos com capacidade para 5,8 $\mathrm{dm}^{3}$ de solo. As adubações fosfatada e potássica foram realizadas de acordo com os resultados da análise do solo. A adubação nitrogenada, via solução aquosa, de acordo com os tratamentos experimentais, foi parcelada em quatro vezes. Quando as plantas apresentavam o número de folhas expandidas indicador da desfolhação, foram colhidas e avaliadas quanto às características morfogênicas. Ao findar o período experimental, as plantas foram colhidas e levadas à estufa, para determinação do teor de MS. A taxa de alongamento foliar (TAlF) aumentou linearmente até $64 \%$ na dose de $120 \mathrm{mg} / \mathrm{dm}^{3}$ de N, em comparação à ausência de nitrogênio. O filocrono reduziu com a adubação nitrogenada. A produção de MS da parte aérea do capim-massai e a relação lâmina:colmo aumentaram linearmente com as doses de $\mathrm{N}$ e a redução do número de folhas expandidas antes da colheita.

Palavras-chave: forragem, matéria seca, morfogênese, Panicum maximum x Panicum infestum, raiz

\section{Morphogenetic and structural characteristics responses of massaigrass under nitrogen fertilization and defoliation}

\begin{abstract}
This work was carried out to evaluate the morphogenetic and structural characteristics of the hybrid Panicum maximum x Panicum infestum cv. Massai in response to four nitrogen doses $\left(0,40,80\right.$ and $\left.120 \mathrm{mg} / \mathrm{dm}^{3}\right)$ and three defoliation intervals (two, three and four completely expanded leaves), in a 4 × 3 factorial treatment combination. The experiment was carried out in greenhouse according to a completely randomized design, with four replications. Sowing was achieved in plastic tray filled with sand and seedlings were transplanted to pots with $5.8 \mathrm{dm}^{3}$ of soil. Pots were thinned to three plants/pot. The phosphate and potash fertilization was accomplished according to soil fertility analysis. The nitrogen fertilization was split in four applications in aqueous solution, according to the experimental doses. As the plants presented the number of expanded leaves, indicating their defoliation interval, they were harvested to $5 \mathrm{~cm}$ from soil level; this harvest marked the beginning of the evaluation period of the morphogenetic and structural characteristics of the grass. At the end of these evaluations, the plants were harvested, dried and weighted. Nitrogen fertilization doses had marked effects on the morphogenetic and structural characteristics of Massaigrass, as well as on its shoot dry weight. Leaf elongation rate (TAlF) showed linear increase of $64 \%$ to $\mathrm{N}$ doses. The phyllochron decreased as nitrogen dose increased. Shoot dry matter weight and lamina:stem ratio increased linearly with the increment of $\mathrm{N}$ doses but decreased as the number of expanded leaves increased before harvest.
\end{abstract}

Key Words: dry matter, forage, morphogenesis, Panicum maximum x Panicum infestum, root

\section{Introdução}

O lançamento de novos cultivares de gramíneas forrageiras resulta de uma demanda por plantas mais competitivas, menos exigentes em fertilidade do solo, com menor sazonalidade de produção e mais resistentes a pragas e doenças, entre outros fatores. Em 2001, o Centro Nacional de Pesquisa em Gado de Corte (EMBRAPA) lançou o cultivar de Panicum maximum $\mathrm{x}$ Panicum infestum, denominado Massai. Estudos básicos de ecofisiologia com o cultivar Massai certamente contribuirão para a predição de melhor estratégia de manejo para que a produção e utilização dessa forrageira sejam otimizadas. 
As características morfogênicas e estruturais são influenciadas por fatores abióticos, como a adubação nitrogenada e temperatura, o manejo aplicado e a freqüência e intensidade de desfolhação. Alguns estudos têm sido conduzidos com o objetivo de avaliar essas características morfogênicas em gramíneas forrageiras e sua relação com a adubação nitrogenada (Pearse \& Wilman, 1984; Alexandrino et al., 2004; GarcezNeto et al., 2002). Avaliações do surgimento de perfilhos (Sbrissia et al., 2001) e folhas (Cavalcante et al., 2002) podem auxiliar no entendimento das relações entre manejo do pastejo e as respostas da forrageira.

Dessa forma, torna-se essencial que estudos de dinâmica de produção das gramíneas forrageiras a partir de avaliações de características morfogênicas e estruturais sejam conduzidos a fim de gerar conhecimentos básicos para definição de estratégias adequadas de manejo, sobretudo quando se considera que, para plantas de clima tropical, o impacto da estratégia de manejo do pastejo sobre suas características morfogenéticas ainda é pouco conhecido (Carvalho et al.,2000), talvez para novos cultivares.

Neste estudo avaliou-se a influência da adubação nitrogenada e do regime de desfolhação (número de folhas expandidas antes do corte) sobre as características morfogênicas e estruturais e a produção de matéria seca da parte aérea e da raiz em plantas de Panicum maximum $\mathrm{x}$ Panicum infestum cv. Massai cultivadas em casa de vegetação.

\section{Material e Métodos}

O experimento foi conduzido em casa de vegetação no Departamento de Zootecnia da UniversidadeFederal de Viçosa, em Viçosa - MG. O município de Viçosa está localizado na região da Zona da Mata Mineira, a 651 m acima do nível do mar ( $20^{\circ} 45^{\prime} 40^{\prime}$ ' de latitude sul e $42^{\circ} 51^{\prime} 40^{\prime}$ ' de longitude oeste), e apresenta tipo climático $\mathrm{Cwa}$, segundo classificação de Koeppen.

Os tratamentos avaliados consistiram da combinação de quatro doses de nitrogênio $\left(0,40,80\right.$ e $\left.120 \mathrm{mg} / \mathrm{dm}^{3}\right)$ e três regimes de desfolhação (três, quatro e cinco folhas completamente expandidas) segundo um fatorial $4 \times 3$, em um delineamento inteiramente casualizado, com quatro repetições, totalizando 48 unidades experimentais.

Os vasos, com capacidade de $5,8 \mathrm{dm}^{3}$, receberam amostras de solo fertilizadas com $300 \mathrm{mg} / \mathrm{dm}^{3}$ de $\mathrm{P}_{2} \mathrm{O}_{5}$ (superfosfato simples), de acordo com análise de fertilidade ( $\mathrm{pH}$ em água $=5,73 ; \mathrm{P}=4,4 \mathrm{mg} / \mathrm{dm}^{3} ; \mathrm{K}=40 \mathrm{mg} / \mathrm{dm}^{3} ; \mathrm{Ca}^{2+}=$ $2,5 \mathrm{cmol}_{\mathrm{c}} / \mathrm{dm}^{3} ; \mathrm{Mg}^{2+}=1,54 \mathrm{cmol}_{\mathrm{c}} / \mathrm{dm}^{3} \mathrm{cmol}_{\mathrm{c}} / \mathrm{dm}^{3} ; \mathrm{H}+\mathrm{Al}=$ $\left.5,3 \mathrm{cmol}_{\mathrm{c}} / \mathrm{dm}^{3}\right)$.
O capim-massai foi semeado em bandejas contendo substrato agrícola comercial e, após 15 dias, foi transplantado para cinco plantas/vaso. O desbaste foi realizado 19 dias após o transplantio, deixando-se três plantas/vaso, e 30 dias após o desbaste foi realizado corte de uniformização, a $5 \mathrm{~cm}$ do solo.

Para avaliação das características morfogênicas, cada uma das três plantas nos vasos recebeu um anel de cor diferenciada, de modo a identificar os perfilhos acompanhados para avaliações morfogênicas. O solo foi mantido próximo à sua capacidade de campo com irrigação diária. As doses de N (uréia), assim como a aplicação de $240 \mathrm{mg} / \mathrm{dm}^{3}$ de potássio (cloreto de potássio), foram parceladas em quatro aplicações, para todos os tratamentos. A primeira aplicação foi feita três dias após o corte de uniformização, independentemente do tratamento, e a segunda variou entre os tratamentos, permitindo-se que as plantas recebessem a adubação nitrogenada conforme o seu desenvolvimento, visto que o regime de desfolhação foi determinado pela expansão completa da folha. Adotou-se esse critério para que as plantas rebrotassem em mesma condição de aporte de N, pois, com o regime de desfolhação, as plantas seriam colhidas em épocas diferentes. Portanto, as plantas que seriam colhidas ao exporem três, quatro e cinco folhas completamente expandidas, respectivamente, receberam a segunda dose de adubação ao expandirem duas, três e quatro folhas. A terceira e a quarta dose foram aplicadas uma e duas semanas após o corte ( $5 \mathrm{~cm}$ de altura), de acordo com as respectivas freqüências. A partir do corte, as plantas foram avaliadas quanto às características morfogênicas e estruturais e a produção de matéria seca.

Diariamente, foram registradas as temperaturas mínima e máxima dentro da casa de vegetação, para expressão dos resultados em graus dia (GD), segundo as equações propostas por Ometto (1981). Os três perfilhos marcados foram avaliados a cada dois dias com registros do dia de aparecimento do ápice foliar, do dia da exposição da lígula, do comprimento final das folhas expandidas e em expansão, da senescência foliar (comprimento total da lâmina menos o comprimento da lâmina ainda verde) e do número de folhas vivas por perfilho. O número total de perfilhos por vaso foi quantificado ao final do período experimental. As características avaliadas foram: taxa de aparecimento foliar (TApF) - folhas/dia e folhas/GD; taxa de alongamento foliar (TAlF) - cm/dia; duração de vida da folha (DVF) - dias; Filocrono (número de dias para o aparecimento de duas folhas consecutivas) - dias e GD; comprimento final da lâmina (CFL); número de folhas vivas por perfilho (NFV); número total de perfilhos (NTP) e taxa de senescência foliar (TSe) $-\mathrm{cm} /$ dia . 
Após a total senescência da primeira folha completamente expandida e não cortada em duas plantas de cada unidade experimental, interromperam-se as avaliações morfogênicas. A partir daí, todas as plantas do vaso foram colhidas e levadas ao laboratório, para separação dos componentes lâmina, colmo + bainha e material morto. A área foliar das plantas de cada vaso foi mensurada antes de as folhas serem levadas à estufa. Após a separação dos componentes das plantas as amostras foram colocadas em estufa de secagem ( $65^{\circ}$ até estabilização do peso), para o cálculo da produção total de MS e das produções de lâmina, colmo e material morto. Avaliou-se também a relação lâmina:colmo. As raízes foram retiradas dos vasos, lavadas em peneiras e encaminhadas para secagem de modo a se calcular a produção de MS radicular.

Os dados referentes às características avaliadas foram submetidos à análise de regressão em função das doses de nitrogênio e do regime de desfolhação, selecionando-se as equações pelo coeficiente de determinação $\left(R^{2}\right)$ e pela significância a $5 \%$ dos coeficientes, de acordo com o teste t. As equações de regressão foram ajustadas com base nas médias de tratamentos, de modo que o $\mathrm{R}^{2}$ foi determinado por: SQReg/SQtrat.

\section{Resultados e Discussão}

A taxa de alongamento foliar (TAlF) do capim-massai foi influenciada $(\mathrm{P}<0,05)$ pela adubação nitrogenada, com os dados ajustados a modelos lineares positivos. Por outro lado, não foi observado efeito $(\mathrm{P}>0,05)$ do regime de desfolhação para essa variável. $\mathrm{O}$ incremento nas taxas de alongamento aumentou em até $64 \%$ para a dose de $120 \mathrm{mg} / \mathrm{dm}^{3}$ em relação à ausência de adubação nitrogenada. Outros trabalhos avaliando os efeitos do $\mathrm{N}$ sobre a taxa de alongamento foliar também apresentaram resultados semelhantes (Gastal \& Nelson, 1994; Alexandrino et al., 2004; Duru \& Ducrocq, 2000).

Esse incremento na TAlF era esperado, pois, conforme Volenec \& Nelson (1984), o efeito da adubação nitrogenada é decorrente da maior produção de células. Essa variável é uma medida de grande importância na análise do fluxo de tecidos das plantas e correlaciona-se positivamente com o rendimento forrageiro, visto que, à medida que a TAlF aumenta, ocorre incremento na proporção de folhas e, conseqüentemente, maior área foliar fotossinteticamente ativa, promovendo maior acúmulo de MS. De fato, neste estudo observou-se correlação positiva $(\mathrm{P}<0,05)$ de 0,52 entre a TAlF e a MS da parte aérea.

Na Figura 2, nota-se que a TApF respondeu linear e positivamente $(\mathrm{P}<0,05)$ tanto às doses de $\mathrm{N}$ como ao regime

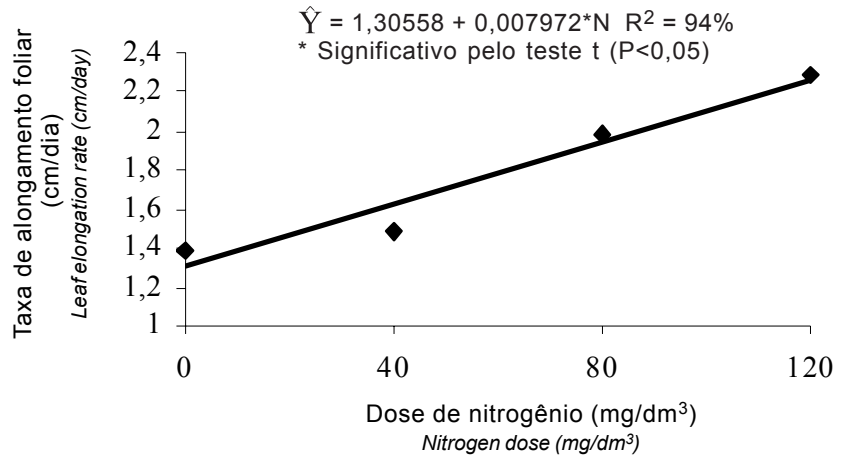

Figura 1 - Efeito das doses de nitrogênio $\left(\mathrm{mg} / \mathrm{dm}^{3}\right)$ sobre a taxa de alongamento foliar de plantas de capim-massai.

Figure 1 - Leaf elongation rate ( $\mathrm{cm} /$ day) of the massaigrass submitted to the nitrogen fertilization.

$\hat{Y}=0,058125+0,000315625^{*} N+0,00032562^{*} F R^{2}=88 \%$
* Significativo pelo teste $t(P<0,05)$

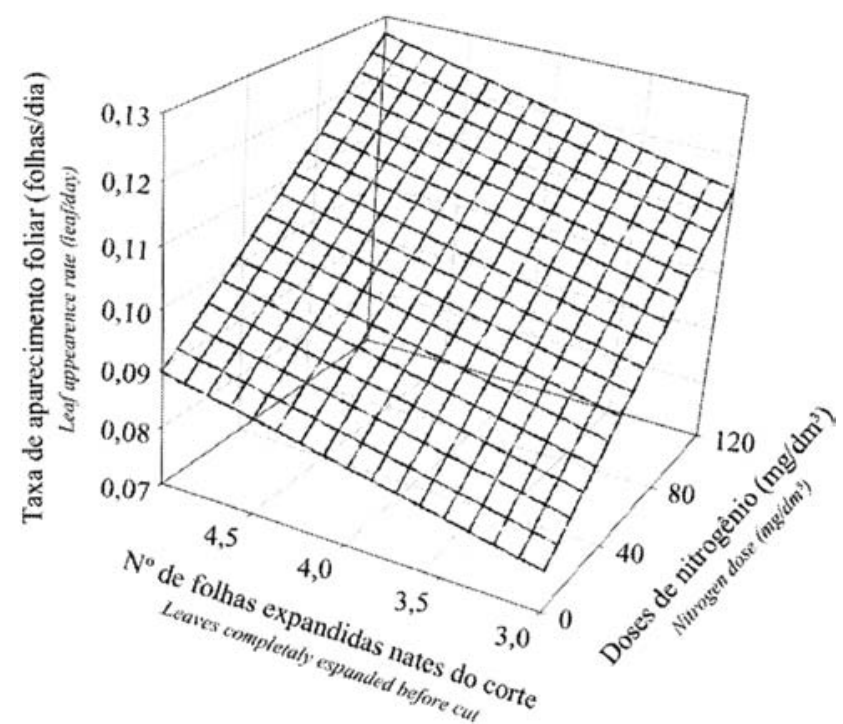

Figura 2 - Efeito das doses do nitrogênio e do regime de desfolhação sobre a taxa de aparecimento foliar de plantas de capim-massai.

Figure 2 - Leaf appearance rate (leaf/day) of the massaigrass submitted to the nitrogen fertilization and defoliation.

de desfolhação avaliado, não havendo interação $(\mathrm{P}>0,05)$ entre os fatores.

Os valores de TApF variaram de 0,059 (para plantas sem adubação nitrogenada e colhidas com três folhas completamente expandidas) para 0,1275 folhas $/ \mathrm{dia}\left(120 \mathrm{mg} / \mathrm{dm}^{3}\right.$ de $\mathrm{N}$ e 5 folhas) (Figura 2). Estudos com capim-massai são ainda incipientes, não havendo, portanto, base comparativa para essa característica. Entretanto, evidenciou-se que a variação observada na $\mathrm{TApF}$ encontra-se próxima ao observada por Garcez Neto et al. (2002), em cv. Mombaça. De acordo com Grant etal. (1981), a TApF é significativamente 
$\hat{\mathrm{Y}}=0,006841+0,00002312^{*} \mathrm{~N} R^{2}=94 \%$

* Significativo pelo teste $t(P<0,05)$

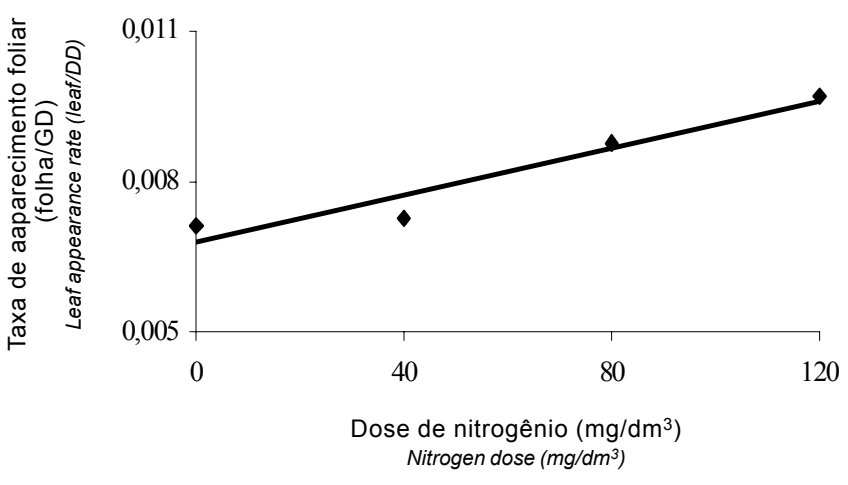

Figura 3 - Efeito das doses de nitrogênio sobre a taxa de aparecimento foliar (folha/GD) em plantas de capimmassai.

Figure 3 - Leaf appearance rate of the massaigrass submitted to the nitrogen fertilization.

influenciada pela taxa de alongamento foliar e pelo comprimento de pseudocolmo, uma vez que esse último determina a distância do percurso para que a folha possa emergir. No caso do capim-massai, neste estudo, à medida que se aumentou o número de folhas expandidas para o corte da planta, a TApF também foi elevada. Desse modo, a distância que a folha percorreu para emergir foi reduzida conforme se aumentou o número de folhas expandidas antes do corte.

A taxa de aparecimento de folhas e seu inverso, o filocrono, é um processo termo-dependente que responde imediatamente a qualquer mudança de temperatura. Avaliando-se a TApF em termos térmicos, observou-se efeito somente da adubação nitrogenada, com resposta linear positiva $(\mathrm{P}<0,05)$ (Figura 3), o que realça a importância de se estabelecer os resultados em graus dia, visto que as plantas não respondem ao calendário humano e seu desenvolvimento é altamente dependente da temperatura.

Neste ensaio o filocrono respondeu $(\mathrm{P}<0,05)$ tanto à adubação nitrogenada quanto ao regime de desfolhação quando os resultados foram expressos em dias, não havendo interação $(\mathrm{P}>0,05)$ entre os fatores (Figura 4). A maior TApF e a mais elevada TAlF permitiram redução no filocrono à medida que se incrementou a adubação nitrogenada.

É desejável que resultados de filocrono sejam expressos em GD, uma vez que diferentes localidades apresentam, em determinado tempo, uma soma calórica diferente, que poderá promover discrepância de resultados. Neste caso, quando se analisa o filocrono em GD, observa-se, à semelhança da TApF, somente efeito linear negativo $(P<0,05)$ da adubação nitrogenada (Figura 5).

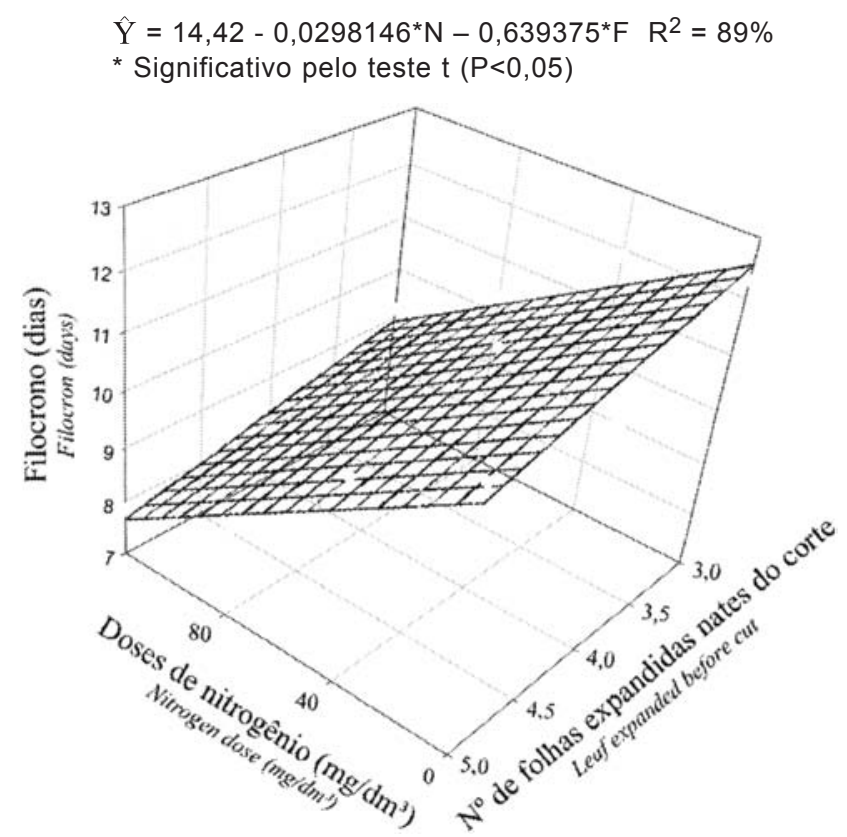

Figura 4 - Filocrono (dias) em plantas de capim-massai em função das doses de nitrogênio e do regime de desfolhação.

Figure 4 - Filocron (days) of the massaigrass submitted to the nitrogen fertilization and defoliation.

A redução do filocrono com a adubação nitrogenada é decorrente do efeito do $\mathrm{N}$ sobre o crescimento de plantas de capim-massai, conferindo à planta maior capacidade de rebrotação, visto que, após a desfolhação, uma rápida recuperação de seu aparato fotossintético pode possibilitar sua sobrevivência ou não na comunidade vegetal. $\mathrm{O} \mathrm{N}$ assume papel de extrema importância ao favorecer essa recuperação, pois é um nutriente essencial em vários de processos fisiológicos (Martuscello et al., 2001).

A duração de vida da folha (DVF) sofreu influência linear negativa $(\mathrm{P}<0,05)$ tanto da adubação nitrogenada como do regime de desfolhação, sem interação $(\mathrm{P}>0,05)$ entre os fatores, de acordo com a equação $\hat{Y}=56,9887$ $0,0806792 \mathrm{~N}-3,85938 \mathrm{D}\left(\mathrm{R}^{2}=0,76\right)$.

$\mathrm{O}$ decréscimo na DVF com as doses de $\mathrm{N}$ é explicado pela maior renovação de tecidos em plantas adubadas, ou seja, plantas sob ausência de $\mathrm{N}$ permanecem mais tempo com suas folhas vivas em detrimento da expansão de novas folhas, em um processo que se evidenciou a partir da TAlF e da maior TApF e, conseqüentemente, da redução no filocrono em plantas adubadas. A estimativa de DVF variou de 45 dias (584 GD), para as plantas sem adubação nitrogenada colhidas com quatro folhas, a 33 dias (435 GD), para as plantas supridas com $120 \mathrm{mg} / \mathrm{dm}^{3}$ de $\mathrm{N}$, também colhidas com quatro folhas. Mazzanti \& Lemaire (1994) ressaltam que, em geral, ocorre diminuição na DVF na alta de disponibilidade de N, em razão da concorrência por luz, 
$\hat{\mathrm{Y}}=147,72-0,374548^{*} \mathrm{~N} \mathrm{R}^{2}=94 \%$

* Significativo pelo teste $t(P<0,05)$

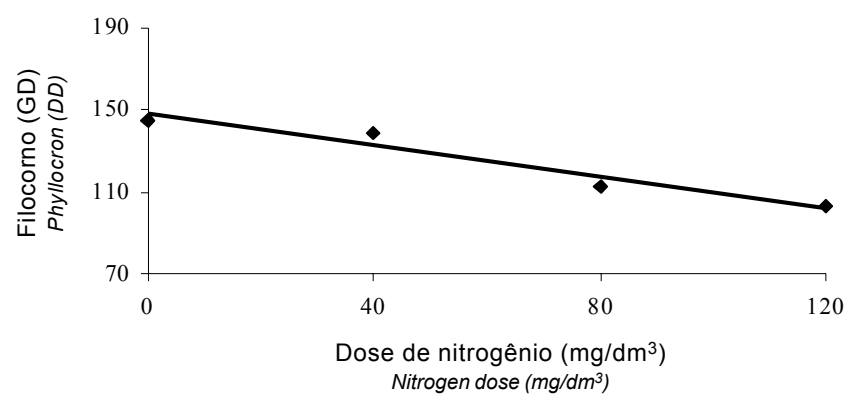

Figura 5 - Filocrono (graus dia) em plantas de capim-massai submetidas a adubação nitrogenada.

Figure 5 - Phyllocron (GD) of the massaigrass submitted of the nitrogen fertilization.

determinada pelo aumento da taxa de alongamento foliar e pelo maior tamanho final das folhas. Os resultados de DVF podem ser melhor entendidos quando analisados em conjunto com a taxa de senescência (TSe). Neste sentido, observou-se correlação negativa $(\mathrm{P}<0,05)$ de 0,48 entre essas variáveis, pois, à medida que se aumentou a adubação nitrogenada $(\mathrm{P}<0,05)$ e diminuiu o número de folhas expandidas antes da colheita $(\mathrm{P}<0,05)$, maior foi a TSe $\left(\hat{Y}=0,367750+0,00196458 \mathrm{~N}-0,024062 \mathrm{D} \mathrm{R}^{2}=88 \%\right)$, talvez pelo fato de que plantas sem adubação de $\mathrm{N}$ apresentam baixa TSe foliar, como estratégia para permanecerem vivas, em razão de seu decréscimo no metabolismo.

O número de folhas vivas (NFV) por perfilho aumentou $(\mathrm{P}<0,05)$ conforme se incrementou a adubação nitrogenada, porém, essa variável não sofreu efeito $(\mathrm{P}>0,05)$ do regime de desfolhação ( $\hat{Y}=3,8049+0,01560 \mathrm{~N} \mathrm{R}^{2}=91 \%$ ). Observou-se que o NFV variou de 4 a 5,77 para as doses de 0 a $120 \mathrm{mg} / \mathrm{dm}^{3}$ de $\mathrm{N}$, respectivamente. Nos tratamento com menores doses de N, ocorreu maior DVF e menor NFV, provavelmente em razão do efeito do $\mathrm{N}$ antecipando o processo de senescência nas plantas com a translocação de nutrientes para auxiliar na expansão de novas folhas.

Outro fator que pode auxiliar o entendimento da relação DVF: NFV é o comprimento final da lâmina foliar (CFL), que respondeu $(\mathrm{P}<0,05)$ tanto à adubação nitrogenada quanto à freqüência de corte, porém com efeito muito mais acentuado da adubação nitrogenada, sem que houvesse interação $(\mathrm{P}>0,05)$ entre os fatores. Portanto, para essa variável, houve aumento linear $(\mathrm{P}<0,05)$ à medida que foram incrementadas as doses de $\mathrm{N}$ e efeito quadrático $(\mathrm{P}<0,05)$ com o aumento do número de folhas expandidas antes da colheita $\left(\hat{Y}=92,48+0,05273 \mathrm{~N}-34,55 \mathrm{D}+4,00 \mathrm{D}^{2} \mathrm{R}^{2}=91 \%\right)$. Embora tenha se observado maior TSe em plantas com maior suprimento de N, o NFV aumentou porque os maiores comprimentos de lâmina foram também detectados nessas plantas. Constatou-se também que, quanto menor o número de folhas expandidas antes do corte (três folhas), maior o tamanho médio das folhas, e que cortes com quatro folhas reduziram essa variável. Neste caso, o CFL variou entre 17,4 e $31,48 \mathrm{~cm}$ para as plantas sem adubação nitrogenada colhidas com quatro folhas e adubadas com $120 \mathrm{mg} / \mathrm{dm}^{3} \mathrm{de}$ $\mathrm{N}$ colhidas com três folhas, respectivamente, evidenciando que, em condições favoráveis de adubação, a divisão celular é favorecida. Outro fator que explica o maior NFV com o aumento das doses de $\mathrm{N}$ é o fato de que em alto aporte de $\mathrm{N}$ ocorreu também maior TApF e, conseqüentemente, compensação na taxa de senescência. Segundo Lemaire \& Agnusdei (1999), a DVF é o determinante no NFV, porém neste experimento, isso não ocorreu. Contudo, considerando-se que o número de folhas revela o potencial fotossintético da planta, os dados indicam que o $\mathrm{N}$ pode aumentar o NFV e o CFL, incrementando sua capacidade de assimilação de carbono, o que também se evidencia com análise da área foliar (AF), que aumentou $(\mathrm{P}<0,05)$ com a adubação nitrogenada (Figura 6), não sofrendo efeito $(\mathrm{P}>0,05)$ do regime de desfolhação. O incremento nessa variável foi de até $116 \%$ para a dose de $120 \mathrm{mg} / \mathrm{dm}^{3}$ de $\mathrm{N}$ em comparação à ausência de N. A adubação nitrogenada tem efeito direto sobre a área foliar fotossintetizante, como conseqüência do incremento da taxa de alongamento foliar.

A MS total apresentou resposta linear positiva $(\mathrm{P}<0,05)$ à adubação nitrogenada e negativa ao regime de desfolhação, sem interação $(\mathrm{P}>0,05)$ entre os fatores $(\hat{\mathrm{Y}}=69,1842+$ $0,185854 \mathrm{~N}-5,578112 \mathrm{D} ; \mathrm{R}^{2}=86 \%$ ). Apesar do aumento na produção, a magnitude destes incrementos foi bem menor que a observada por Garcez Neto et al. (2002), que registrou aumento de até $456 \%$ na maior dose de $\mathrm{N}\left(200 \mathrm{mg} / \mathrm{dm}^{3}\right)$ em capim-mombaça. Independentemente da magnitude dos efeitos de N sobre a produção de MS, a influência desse nutriente pode ser atribuída ao aumento na TApF (Thomas, 1983), que reflete na TAlF, contribuindo para o crescimento do vegetal, resultando em aumento na área foliar (Paciullo et al., 1998; Alexandrino et al., 2004).

Plantas colhidas com três folhas expandidas apresentaram maior produção de MST que as colhidas com quatro e cinco folhas, o que não era esperado, uma vez que, à medida que se reduz a frequência de corte, aumenta a produção de MS (da Silva \& Pedreira, 1997). De qualquer forma, o efeito da desfolhação, por meio da freqüência ou intensidade com que é realizada, reflete-se diretamente na condição das plantas que compõem a comunidade vegetal, determinando sua capacidade de crescimento, produtividade e persistência (Nabinger, 2001). 
Houve aumento na produção de MS de lâmina foliar e colmo à medida que se incrementaram as doses de $\mathrm{N}(\mathrm{P}<0,05)$ e que aumentou o número de folhas expandidas antes do corte $(\mathrm{P}<0,05)$. Esse aumento na produção pode ser representado pelas respectivas equações $\hat{Y}=35,42+0,123408 * \mathrm{~N}$ $-2,02187 * \mathrm{D}\left(\mathrm{R}^{2}=95 \%\right)$ para lâmina foliar e $\hat{\mathrm{Y}}=24,79+$ $0,067916 * \mathrm{~N}-3,0562 * \mathrm{D}\left(\mathrm{R}^{2}=90 \%\right)$ para colmos.

A maior produção de MS de lâminas foliares com as doses de nitrogênio é coerente com a maior AF dessas plantas (Figura 6), constatando-se alta correlação $(\mathrm{P}<0,05)$ $(\mathrm{r}=0,88)$ entre essas duas variáveis. A produção de MS laminar é uma característica importante para o crescimento das forrageiras, visto que a lâmina é o componente mais fotossinteticamente ativo da folha (Parsons et al., 1983). Segundo Vilela et al. (1978), a TAlF também se relaciona positivamente com o vigor de rebrotação e o acúmulo de MS. De fato, neste ensaio, encontrou-se alta correlação $(\mathrm{P}<0,05)$ entre a TAlF e a produção de MS da lâmina foliar $(r=0,87)$.

À semelhança da lâmina foliar, a produção de MS de colmo de capim-massai também aumentou com as doses de N. Os valores variaram entre $10 \mathrm{~g} /$ vaso para plantas sem adubação nitrogenada e colhidas com cinco folhas e 23,5 g/ vaso para plantas adubadas com maior dose de $\mathrm{N}$ e colhidas com três folhas.

A relação lâmina:colmo foi influenciada $(\mathrm{P}<0,05)$ tanto pelo $\mathrm{N}$ quanto pela frequência, sem interação $(\mathrm{P}>0,05)$ entre os fatores $(\hat{\mathrm{Y}}=1,10375-0,001510 * \mathrm{~N}+0,279687 * \mathrm{D}$; $\mathrm{R}^{2}=78 \%$ ). Pode-se, portanto, admitir que o alongamento de colmo de capim-massai neste experimento e seu conseqüente aumento de peso não foram suficientes para comprometer a relação lâmina:colmo, pois a produção de lâmina foliar também apresentou comportamento linear positivo á medida que a adubação nitrogenada foi aumentada e o número de folhas expandidas foi diminuído antes do corte. Assim, a adubação nitrogenada produziu efeito mais intenso na produção de folha que na produção de colmo aumentando a relação lâmina:colmo.

Quanto à MS do sistema radicular do capim-massai, ao contrário de todas as outras variáveis analisadas, não se detectou efeito da adubação nitrogenada $(\mathrm{P}>0,05)$. Esses resultados são contrários aos da literatura, que sugerem que plantas em solos deficientes em $\mathrm{N}$ tendem a aumentar sua massa radicular como forma de explorar maior volume de solo. Por outro lado, observou-se relação linear positiva $(\mathrm{P}>0,05)$ entre a MS da raiz e a desfolhação $(\hat{\mathrm{Y}}=17,5208+18,7031 * \mathrm{D}$; $\mathrm{R}^{2}=89 \%$ ), ou seja, conforme aumentou o número de folhas expandidas antes do corte, houve incremento na MS da raiz, indicando que as plantas cortadas com menor número de folhas expandidas têm seu sistema radicular comprometido,

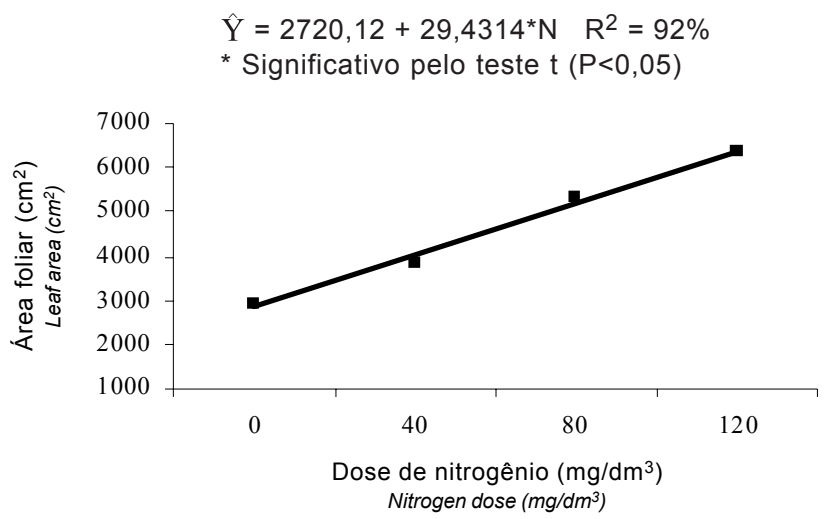

Figura 6 - Área foliar $\left(\mathrm{cm}^{2}\right)$ de plantas de capim-massai em função das doses de nitrogênio.

Figure 6 - Leaf area of the massaigrass submitted to the nitrogen fertilization.

pois o estresse da desfolha precoce e drástica $(5 \mathrm{~cm}$ de altura $)$ promove remobilização de reservas das raízes para recuperação da área foliar (Thornton \& Millard, 1997).

O número de perfilhos/vaso não foi influenciado $(\mathrm{P}>0,05)$ pela freqüência de corte, mas apresentou resposta linear positiva $\left(\hat{\mathrm{Y}}=47,84+0,22283 * \mathrm{~N} ; \mathrm{R}^{2}=93 \%\right)$ à adubação nitrogenada.

Observaram-se aumentos de 26, 30 e $61 \%$ no número de perfilhos para as doses de 40, 80 e $120 \mathrm{mg} / \mathrm{dm}^{3}$ de $\mathrm{N}$, respectivamente, em relação às plantas que não receberam adubação nitrogenada, não havendo maior evidência do efeito do $\mathrm{N}$ nessa variável em relação à TAlF e TApF.

$\mathrm{O}$ número total de perfilhos por vaso apresentou correlação positiva $(\mathrm{P}<0,05)$ com o NFV $(\mathrm{r}=0,74)$ e com a TApF $(\mathrm{r}=0,72)$, corroborando os dados de Garcez Neto et al. (2002) e Zarrough (1984). De fato, a TApF tem relação estreita com o perfilhamento, uma vez que a produção de massa por perfilho é dependente dos efeitos da disponibilidade dos fatores do meio sobre essa variável (Nabinger, 2001). Também a taxa de aparecimento de perfilhos na ausência de competição é decorrente do sincronismo entre o desenvolvimento das folhas e o perfilhamento, gerando-se o conceito de "ocupação de sítios" (Davies, 1974).

\section{Conclusões}

A adubação nitrogenada exerce efeito positivo nas taxas de alongamento e no aparecimento foliar em plantas de capim-massai. O processo de senescência foliar desta forrageira é acelerado com o aumento das doses de nitrogênio, reduzindo a duração média de vida das folhas.

O número de perfilhos e folhas vivas e o comprimento final da lâmina foliar apresentam resposta linear positiva ao aumento da adubação nitrogenada. 
A taxa de alongamento foliar e a produção de matéria seca da raiz, lâmina e colmo em plantas de capim-massai aumentam conforme o número de folhas expandidas antes do corte. A taxa de senescência, o comprimento final da lâmina e a duração de vida das folhas diminuem com o aumento do número de folhas expandidas antes do corte.

A produção de matéria seca da parte aérea aumenta à medida que se incrementa a adubação nitrogenada e que eleva o número de folhas expandidas antes do corte.

\section{Literatura Citada}

ALEXANDRINO E.; NASCIMENTO JR., D.; MOSQUIM, P.R. et al. Características morfogênicas e estruturais na rebrotação da Brachiaria brizantha cv. Marandu submetida a três doses de nitrogênio. Revista Brasileira de Zootecnia, v.33, n.6, p.1372-1379, 2004.

CARVALHO, C.A.B.; da SILVA, S.C.; SBRISSIA, A.F. et al. Demografia de perfilhamento e taxas de acúmulo de matéria seca em capim "tifton 85" sob pastejo. Scientia Agrícola, v. 57, n.4, p.591-600, 2000.

CAVAlCANTE, M.A.B.; GOMIDE, J.A.; PEREIRA, O.G. et al. Características morfogênicas e estruturais do relvado de Brachiaria brizantha cv. Basilisk sob pastejo, em diferentes alturas. In: REUNIÃO ANUAL DA SOCIEDADE BRASILEIRA DE ZOOTECNIA, 38., 2002, Recife. Anais...Recife: Sociedade Brasileira de Zootecnia, 2002. CD-ROM.

DA SILVA, S.C.; PEDREIRA, C.G.S. Princípios de ecologia aplicados ao manejo da pastagem. In: FAVORETTO, V.; RODRIGUES, L.R.A.; RODRIGUES, T.J.D. (Eds.) ECOSSISTEMA DE PASTAGENS, 3., 1997, Jaboticabal. Anais... Jaboticabal: Universidade Estadual Paulista, 1997. 341p.

DAVIES, A. Leaf tissue remaining after cutting and regrowth in perennial ryegrass. Journal of Agricultural Science, v. 82, p.165-172, 1974.

DURU, M.; DUCROCQ, H. Growth and senescence of the successive leaves on a Cocksfoot tiller. Effect of nitrogen and cutting regime. Annals of Botany, v.85, p.645-653, 2000.

GARCEZ NETO, A.F.; NASCIMENTO JR., D.; REGAZZI, A.J. et al. Respostas morfogênicas e estruturais de Panicum Maximum cv. Mombaça sob diferentes níveis de adubação nitrogenada e alturas de corte. Revista Brasileira de Zootecnia, v.31, n.5, p.1890-1900, 2002.

GARCEZ NETO, A.F.; NASCIMENTO JR., D.; REGAZZI, A.J. et al. Avaliação de características morfogênicas de Panicum maximum $\mathrm{cv}$. Mombaça em resposta à adubação nitrogenada e alturas de corte. In: REUNIÃO ANUAL DA SOCIEDADE BRASILEIRA DE ZOOTECNIA, 38., 2002, Recife. Anais... Recife: Sociedade Brasileira de Zootecnia, 2002. CD-ROM.

GASTAL, F.; NELSON, C.J. Nitrogen use whitin the growing leaf blade of tall fescue. Plant physiology, v.105, p.191-197, 1994.

GRANT, S.A.; BARTHRAM, G.T.; TORVEL, L. Components of regrowth in grazed and cut Lolium perenne swards. Grass and Forage Science, v.36, p.155-168, 1981.
LEMAIRE, G.; AGNUSDEI, M. Leaf tissue turn-over and efficiency of herbage utilization. In: LEMAIRE, G. (Ed.) In: GRASSLAND ECOPHYSIOLOGY AND GRAZING ECOLOGY, 1999, Curitiba Proceedings... Curitiba: 1999. p.165-186.

MARTUSCELlO, J.A.; GOMES, R.A.; CUNHA, D.N.F.V. et al. Acúmulo de biomassa e uso do nitrogênio em plantas de Pennisetum purpureum (Schum.) cv. Mineiro, supridas com formas orgânicas de nitrogênio. In: CONGRESSO BRASILEIRO DE FISIOLOGia Vegetal, 8., 2001, Ilhéus. Anais... Ilhéus: Sociedade Brasileira de Fisiologia Vegetal, 2001. CD-ROM

MAZZANTI, A.; LEMAIRE, G.; GASTAL, F. 1994. The effect of nitrogen fertilization upon the herbage production of tall fescue swards continuously grazed with sheep. 1. Herbage growth dynamics. Grass and Forage Science, v.49, p.111-120.

NABINGER, C. Manejo da desfolha In: SIMPÓSIO SOBRE MANEJO DA PASTAGEM, 18., 2001, Piracicaba. Anais... Piracicaba: Escola Superior de Agricultura Luiz de Queiroz, 2001. p.231-251.

OMETTO, J.C. Bioclimatologia vegetal. São Paulo: Ceres, 1981 $440 \mathrm{p}$.

PACIULlo, D.S.C.; GOMIDE, J.A.; RIBEIRO, K.G. Adubação nitrogenada de capim-elefante cv. Mott 1. Rendimento forrageiro e características morfofisiológicas ao atingir 80 e $120 \mathrm{~cm}$ de altura. Revista Brasileira de Zootecnia, v.27, n.6, p.1069-1075, 1998.

PARSONS, A.J.; LEAFE, E.L.; COLLET, B. et al. The physiology of grass production under grazing. 1. Characteristics of leaf and canopy photesyntesis of continuously grazed swards. Journal Applied Ecology, v.20, p.117-136, 1983.

PEARSE, P.J.; WILMAN, D. Effects of applied nitrogen on grass leaf initiation, development and death in field swards. Journal agriculture Science, v. 103, n.2, p.405-413, 1984.

SBRISSIA, A.F.; DA SILVA, S.C.; CARVALHO, C.A.B. et al. Tiller size/population density compensation in grazed coastcross bermudagrass swards. Scientia Agricola, v.58, n.4, p.655-665, 2001.

THOMAS, H. Analysis of the nitrogen response of leaf extension in Lolium temulentum seedlings. Annals of Botany, v.51, p.363-371, 1983.

THORNTON, B.; MILLARD, P. Increased defoliation frequency depletes remobilization of nitrogen for leaf growth in grasses. Annals of Botany, v.80, p.89-95. 1997

VILELA, H.; GOMIDE, J.A.; MAESTRI, M. Efeito da idade da planta ao primeiro corte e dos intervalos entre cortes sobre o rendimento forrageiro, teor de carboidratos solúveis na base da planta, índice de área foliar e interceptação da luz em aveia forrageira. Revista Brasileira de Zootecnia, v.7, n.1, p.79-83, 1978.

VOLENEC, J.J.; NELSON, C.J. Responses of tall fescue leaf meristems to $\mathrm{N}$ fertilization and harvest frequency. Crop Science, v.23, p.720-724, 1983.

ZARROUGH, K.M.; NELSON, C.J.; SLEPER, D.A. Interrelationships between rates of leaf appearance and tillering in selected tall fescue populations. Crop Science, v.24, p.565-569, 1984. 